\title{
Troubleshooting in Immunohistochemistry with their Remedies
}

\author{
${ }^{1}$ Vanishri C Haragannavar, ${ }^{2}$ Shankargouda B Patil, ${ }^{3}$ Roopa S Rao, ${ }^{4}$ Shwetha K Nambiar \\ ${ }^{5}$ Dominic Augustine, ${ }^{6} \mathrm{SV}$ Sowmya
}

\begin{abstract}
Aim: The aim of the present study was to review the importance of various steps involved in immunohistochemistry (IHC) and highlight the troubleshootings encountered at each phase of the procedure with possible remedies.
\end{abstract}

Introduction: Immunohistochemistry is often employed to explore tissue/cell antigens that vary from amino acids, proteins, infectious agents, and specific cellular group in health and disease. It is a vital tool for scientific research and also an adjunct technique for the exclusion of differential diagnosis that may be missed by routine stains. Although IHC is well practiced, there are several hurdles that could be encountered during each step of immunohistochemical procedure, i.e., preparation of slide to incubation with antibodies, interpretation and quantification of the desired expression that finally influences the staining of tissue.

Clinical significance: An accurate and proper diagnosis of a pathology is key for the successful treatment by a clinician/ surgeon, as IHC acts as an adjunct in the diagnosis of challenging lesions. Hence, it is absolute necessary for a pathologist to have a thorough knowledge of immunohistochemical procedure and remedies to overcome the hurdles encountered during the procedure to obtain an ideal IHC-stained slide for diagnosis.

Keywords: Analytical phase, Antigen retrieval, Immunohistochemistry, Postanalytical phase, Preanalytical phase, Remedies, Troubleshooters.

How to cite this article: Haragannavar VC, Patil SB, Rao RS, Nambiar SK, Augustine D, Sowmya SV. Troubleshooting in Immunohistochemistry with their Remedies. World J Dent 2018;9(4):333-341.

\section{Source of support: Nil}

Conflict of interest: None

\section{INTRODUCTION}

Immunohistochemistry is a well-known adjunctive method for the routine histopathology in the diagnosis

\footnotetext{
1,3-6 Department of Oral Pathology and Microbiology, Faculty of Dental Sciences, M.S. Ramaiah University of Applied Sciences Bengaluru, Karnataka, India

${ }^{2}$ Division of Oral Pathology, Department of Maxillofacial Surgery and Diagnostic Sciences, College of Dentistry, Jazan University Jazan, Kingdom of Saudi Arabia

Corresponding Author: Vanishri $\mathrm{C}$ Haragannavar, Department of Oral Pathology and Microbiology, Faculty of Dental Sciences M.S. Ramaiah University of Applied Sciences, Bengaluru Karnataka, India, e-mail: vani.haragannavar@gmail.com
}

of diseases and research. It has drastically improved the outlook for advanced diagnostic tests. Although various advanced techniques like flow cytometry, in situ hybridization, and molecular diagnostic tests have come in vogue, diagnostic problems that occur in routine histopathology are yet to be addressed. Immunohistochemistry is the most commonly employed tool for the enhancement and identification of the localization of an antigen in formalin-fixed paraffin-embedded (FFPE) tissues. Theoretically, IHC seems to be quite a simple technique, but in reality, there are too many hurdles we might as well encounter during the initial step to end of the procedure. This can be compared with churning a new recipe that involves trial and error with many permutations and combinations along with expertise to standardize. As we know, there are many confounding factors that can influence the configuration of the antigens and epitopes. This in turn can impact the quality of the staining and interpretation. Hence, it is important to standardize the procedure with the background of thorough knowledge on the technical aspects of an IHC staining along with the importance of ongoing quality control. So, this review focuses on the troubleshooting encountered during each phase of immunohistochemical procedure along with their counter measures from our personal experience and literature search. As we know, the quality of IHC staining is influenced by several factors such as preanalytic, analytic, and postanalytic variables. For better understanding, the above-mentioned sequence is abided with (Flow Chart 1). ${ }^{1,2}$

\section{PREANALYTIC PHASE}

It is an initial phase of IHC procedure that involves various steps of tissue preparation from collection of the sample, to fix and process. This facilitates to prepare the tissue blocks for the sectioning and final treatment with antibody. This phase might pose several problems resulting in false-positive and false-negative results. Thereby, we address the remedies in Table 1.

- Handling and grossing of the tissue: This step, although initial, is crucial to ensure the quality of IHC staining. Tissues ready for processing need to have a minimum thickness of 2 to $3 \mathrm{~mm}$ and not be crowded in the tissue holders. The fate of the IHC will 
Flow Chart 1: Troubleshooters in immunohistochemistry at different phases of procedure

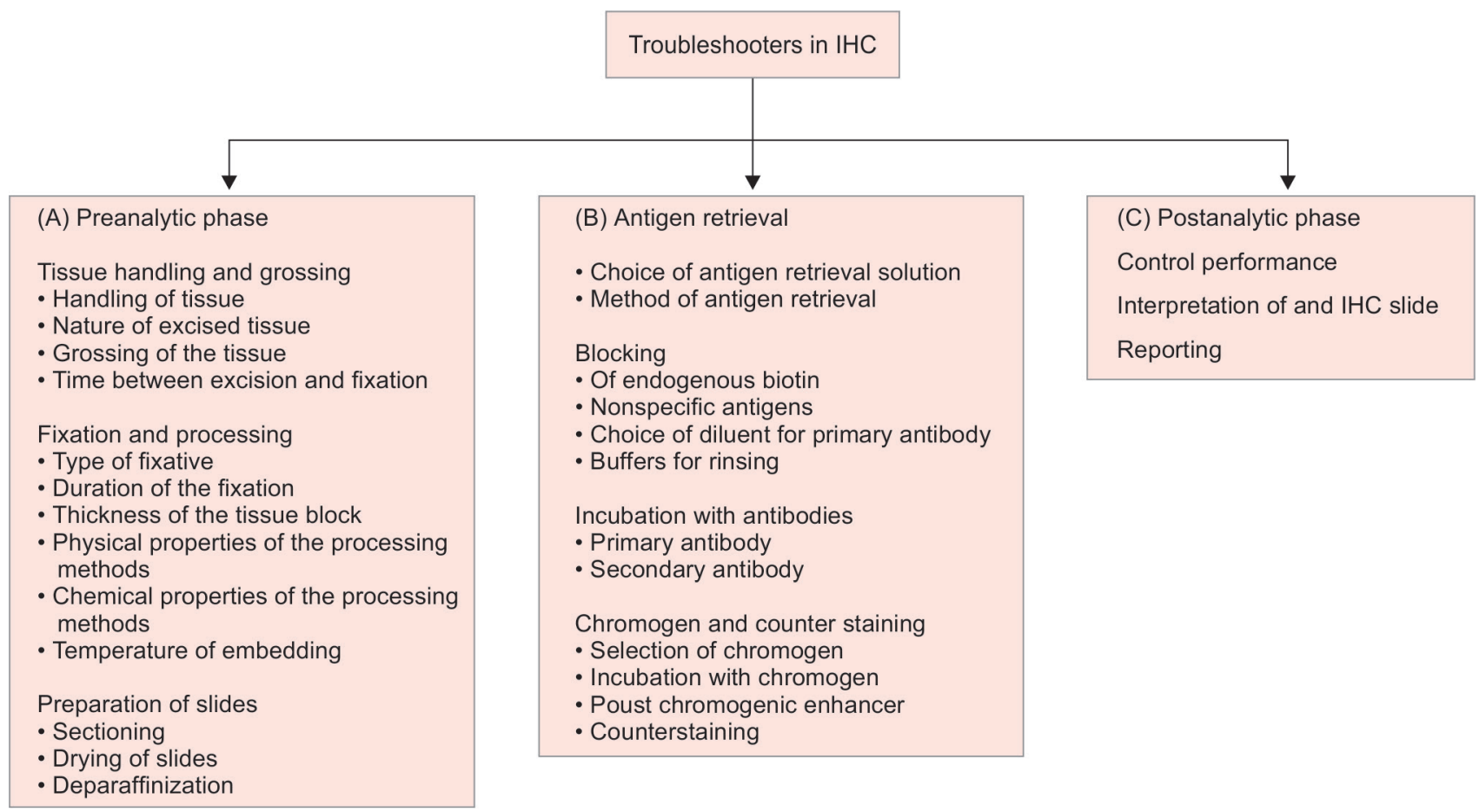

Table 1: Troubleshooters and their remedies during preanalytical phase

(A) Preanalytic phase ${ }^{1-8}$

\begin{tabular}{ll}
\hline Steps & Problems/causes \\
\hline Fixation & Delayed fixation \\
& a. An $\uparrow$ sed proteolytic degradation results in weak or absence \\
& or irreversible staining which in turn depends on the antigen \\
& Results in nonspecific binding to unrelated molecules due \\
& to proteolysis
\end{tabular}

Remedies

Prolonged fixation

a. Secondary shrinkage, negative or weak staining, excessive a. Although overfixed, tissues should have a set of cross-linking and contamination of the tissue

\section{b. Antigen masking/loss of cellular morphology}

Underfixation (short time fixation)

a. Nonspecific staining-unfixed tissues tend to bind all the reagents nonspecifically

b. Edge staining: variation in the fixation at the edges and center of the tissues (Halo effect)

c. Ungrossed tissue results in gradient of staining on edge than the center of the tissue

Preparation Excessive staining due to improper slide preparation

of slides

b. Sections not completely deparaffinized/dewaxed (loss of tissue morphology)

c. Slide adhesive inappropriate or too thick

d. Tissue section too thick

No staining

a. Use of charged slides with expiry date three slides with progressive doubling of the time of exposure to protease or heat-induced epitope retrieval.

Increase the antibody concentrations, prolong the incubation of the reagents, or amplify the signal

a. Postsurgery, organs and solid tumors need to be grossed immediately and fixed within 30 min to ensure rapid onset of fixation

b. Proper AR using recommended timings and solutions for each antibody given in the datasheet

a. Tissues have to be sliced to thin sections of 2-3 mm

b. Fixative to tissue volume ratio should be 1:9 parts

c. Tissues have to be sliced to thin sections of 2-3 mm

a. Reduce incubation time; incubate in a humidified chamber.

b. Use fresh dewaxing solutions

c. Use adhesives specific for $\mathrm{IHC}$ or positive charged slides

d. Prepare thinner sections of 3-4 $\mu \mathrm{m}$

a. Check the manufacturer's expiry date and discard the slides; use new set of charged slides 
be determined by standard routine hematoxylin and eosin stain or it is like "Junk in Junk out."

- Fixation: It is a well-known fact that to define the morphology and cellular details including specific distribution of molecules in a tissue, an immediate tissue fixation is pivotal, as it maintains the integrity of a cell and prevents autolysis. ${ }^{3-5}$

In the field of IHC, fixation is required to localize and optimize accurately the presence of antigens and the distribution of the various epitopes (antibody binding sites) on which the principle of IHC is dependent. The fixative can veneer epitopes and result in the loss of their immunoreactivity. Therefore, the choice of suitable fixative plays a very important role in the success of immunohistochemical staining. A choice of fixative varies from antibody to antibody, but the most commonly preferred fixative for most of the tissues is $10 \%$ neutral buffered formalin. It forms cross-links or covalent bridges between and within proteins and nucleic acids, forming hydroxyl methyl groups that contains an active hydrogen or primary tertiary amines that further leads to condensation reaction, ${ }^{4}$ while fixation in alcohol results in poor staining of the epithelium and connective tissue. Alcohol fixes tissues but causes severe shrinkage. Therefore, alcohol is not recommended as a substitute for formalin except in extreme emergencies. It also makes the tissue brittle. ${ }^{6}$ It is necessary to preserve antibody binding sites (epitopes) for their accessibility and ability to bind antibodies. Thus, the choice of suitable fixative can influence the success of IHC. Also, concentration and duration of the fixative can equally impact the staining. One excellent indicator of poor fixation is the loss of details of extravasated red blood cells. ${ }^{2,7}$ Variation in the timings of fixation can affect the antigenicity of a tissue like delayed fixation, short fixation, or prolonged fixation (Table 1). In order to avoid errors, formalin should be used as a standard fixative.

- Processing: "Tissue processing" is a consecutive step postfixation to make the tissue suitable to embed in a wax that will enable microtome sectioning of the tissues. At this juncture, problems may be triggered at various points, from embedding of the tissue to quality control.

- Preparation of slides: This step in the IHC is basic and crucial. It is defined as a skilled process to cut the tissues into ultrathin sections of 3 to $4 \mu \mathrm{m}$ (Fig. 1E). These sections have to be floated in a water bath and lifted on charged slides or on the slides with polyL-lysine adhesive material. It is recommended that the section has to lie flat on slide in order to avoid air entrapment. However, thicker sections pose difficulties during interpretation as a multilayered cell artifact. Ideally, commercially available charged glass slides are recommended for IHC staining that come with positive and negative charges. The positive charges of a slide attracts the negative charges of tissue proteins formed due to the formalin fixation and prepares the tissue for antigen retrieval (AR). The tissues picked on the charged slides have shelf life depending upon the type of antibody.

Furthermore, it is subjected for dewaxing (Fig. 1F) and dehydration. The slides have to be kept at room temperature for minimum of 15 minutes and kept in upright position to drain the excess water. Before the initiation of staining, slides have to be heated at $60^{\circ} \mathrm{C}$ for 30 minutes.

\section{ANALYTICAL PHASE}

\section{Antigen Retrieval}

The principle of AR is to unmask the antigens from FFPE-sectioned tissues to achieve the successful staining by high-temperature heating at/above 120a by treating the FFPE tissue with strong alkaline solution (buffers) (Figs 1A and B and Tables 2 and 3). Although AR facilitates detection of antigens, background staining or antigen detection in unusual locations is not uncommon with harsh AR methods and can preclude diagnostic interpretation. ${ }^{9,10}$

There are various confounding factors like choice of solution, method, duration of AR, restraints, possible false-positive staining, and the mechanism of AR. All of these can influence the AR in IHC for better antigenantibody bonding. As mentioned earlier, buffers and methods vary from antibody to antibody and not all antigen structures which are altered by formalin can be restored using conventional AR protocols. Therefore, a "test battery" can be used to set up an optimal AR protocol for those antigens under analysis. ${ }^{10}$

Even though the technique of AR is very simple, it is essential to understand the mechanism and factors that can influence the efficacy of IHC staining. Two major factors, the heating conditions (temperature and time) and the $\mathrm{pH}$ value of the AR solution, are important. To achieve a better staining in IHC, a "test battery" approach is recommended. ${ }^{10}$ Test battery is a rapid screening approach to develop an optimal protocol for any antibody to be tested. It is an important step in achieving the maximal retrieval level for formalin-masked antigens with a varied fixation timings, to standardize and improve the immunostaining results and false-negative staining. ${ }^{9-12}$

Higher temperature AR treatment for few proteins might cause a negative staining of IHC. In such cases, a lower temperature heating treatment or a combination of retrieval protocol (heat and enzyme digestion) may yield better results than the individual method. ${ }^{9}$ 


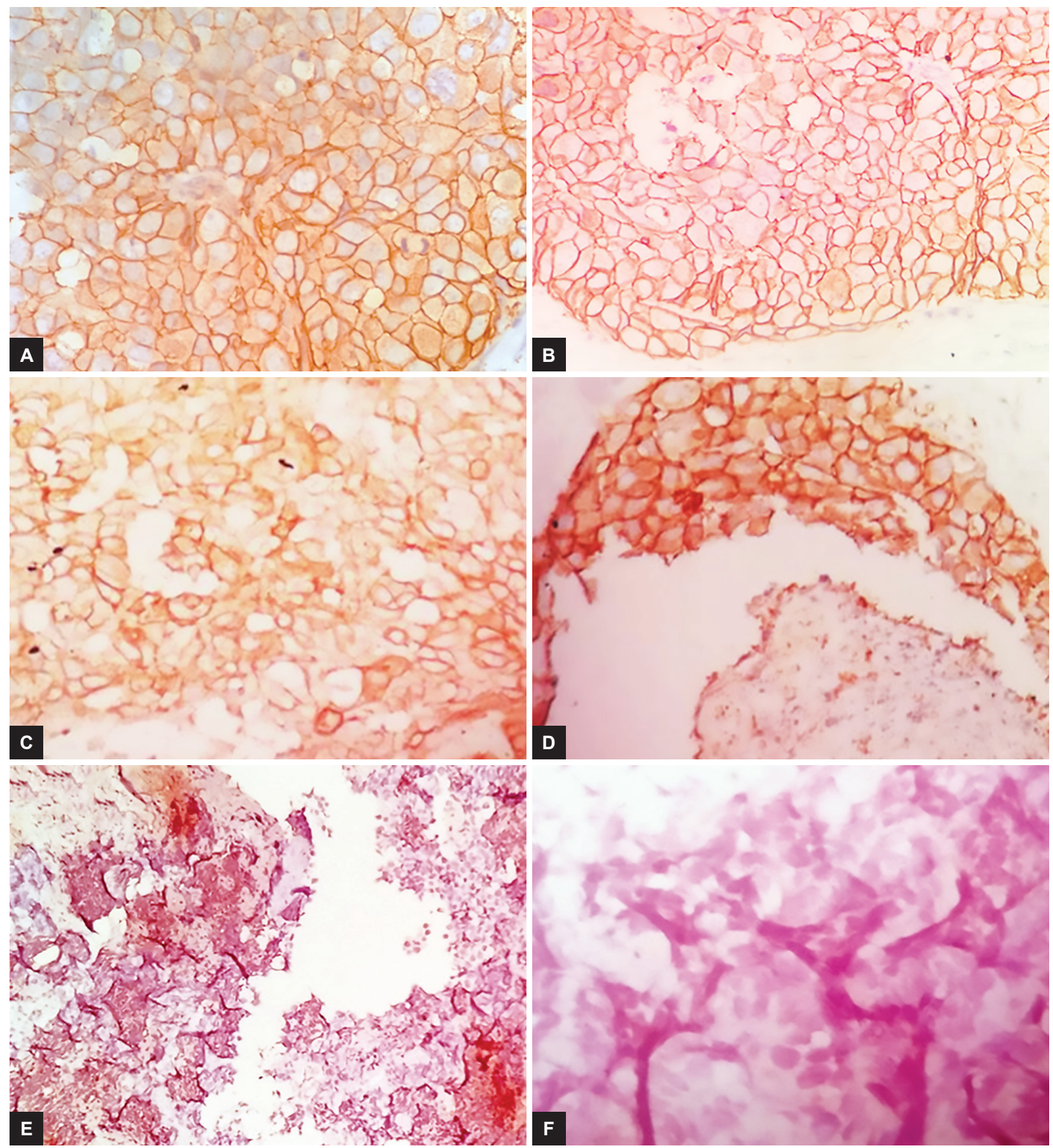

Figs $1 \mathrm{~A}$ to $\mathrm{F}$ : Photomicrographs of immunohistochemically stained sections of oral squamous cell carcinoma of buccal mucosa showing variation in the staining of antibody ERBB2 due to problems encountered at various stages of IHC procedure: under $100 \times$ magnification. (A) Citrate buffer AR solution for ERBB2 antibody showing minimum nonspecific background staining. (B) Ethylenediaminetetraacetic acid buffer AR solution for ERBB2 antibody showing high background staining. (C) False-positive staining —without quenching. (D) True-positive staining—with quenching. (E) Folded tissue showing nonspecific staining. (F) Negative staining due to improper dewaxing

\section{Quenching/Blocking}

Quenching helps to avoid or minimize the false-positive staining (incorrect identification of positive signal) that can occur due to the following reasons (Figs 1 C and D and Table 3$)^{13,14}$ :

- The presence of abundant endogenous peroxidase in red blood cells, granulocytes, and neurons as noted in liver, kidney, and vascular areas
- The presence of endogenous biotin interference

- Nonspecific ionic interactions

- Nonspecific hydrophobic interactions

One of the clinchers in IHC standardization has been the exposure of endogenous biotin as an impenetrable factor along with measures to minimize its contribution to cause staining errors. To visualize epitope antibody interaction, chromogenic detection methods use a 


\begin{tabular}{|c|c|}
\hline \multicolumn{2}{|c|}{ Table 2: List of AR methods } \\
\hline Method of $A R^{9,10}$ & Buffers and $p H$ recommended \\
\hline $\begin{array}{l}\text { Protease digestion: } \\
\text { enzyme-induced } \\
\text { epitope retrieval (EIER) }\end{array}$ & $\begin{array}{l}\text { Pronase } \\
\text { Trypsin } \\
\text { Ficin } \\
\text { Pepsin }\end{array}$ \\
\hline \multicolumn{2}{|l|}{$\begin{array}{l}\text { Heat-induced epitope } \\
\text { retrieval (HIER) }\end{array}$} \\
\hline a. Water bath & $\begin{array}{l}\text { a. } 0.1 \mathrm{M} \text { ethylenediaminetetraacetic } \\
\text { acid at } \mathrm{pH} 8\end{array}$ \\
\hline b. Autoclave & b. Calcium chloride \\
\hline c. Pressure cooker & c. Magnesium chloride \\
\hline d. Microwave & d. $0.1 \mathrm{M}$ citrate buffer at $\mathrm{pH} 6$ \\
\hline e. Steam heating & e. $0.5 \mathrm{M}$ Tris base buffer at $\mathrm{pH} 10$ \\
\hline $\begin{array}{l}\text { f. Automated (online } \\
\text { retrieval) }\end{array}$ & $\begin{array}{l}\text { f. } 0.05 \mathrm{M} \text { glycine- } \mathrm{HCl} \text { buffer } \\
\text { g. } 1 \% \text { periodic acid }\end{array}$ \\
\hline & $\begin{array}{l}\text { NOTE: Above-mentioned buffers can } \\
\text { be used with any of the AR methods }\end{array}$ \\
\hline
\end{tabular}

conjugated peroxidase enzyme. This enzyme activity has to be blocked to avoid nonspecific staining (Fig. 2). ${ }^{14,16}$

- Endogenous peroxidase: The presence of peroxidase or phosphatase in the tissue can be identified by treating the tissue with 3,33-diaminobenzidine. Postrehydration, the tissue imparts brown color. ${ }^{12,13}$ To overcome the endogenous peroxidase activity in IHC, tissues have to be treated with 3 to $10 \%$ of $\mathrm{H}_{2} \mathrm{O}_{2}$ for 15 to 20 minutes at room temperature before incubating with horseradish peroxidase (HRP) conjugated secondary antibody so as to quench the endogenous peroxidase to lessen the nonspecific staining. Another reagent phenylhydrazine is capable of blocking the endogenous peroxidase activity and thus prevents the background adsorption of HRP and enhances the IHC staining. ${ }^{17}$

Table 3: Troubleshooters and their remedies during analytical phase

\begin{tabular}{ll}
\hline Analytical phase & \\
\hline Steps & Problems/causes \\
\hline Quenching/blocking & $\begin{array}{l}\text { Excessive background staining } \\
\text { a. Omission of endogenous blocking step } \\
\text { b. Inadequate protein blocking }\end{array}$ \\
& $\begin{array}{l}\text { c. Inadequate blocking of endogenous avidin- } \\
\text { binding activity }\end{array}$ \\
& d. Inadequate blocking of endogenous biotin \\
& e. Blocking serum from improper species
\end{tabular}

Incubation-primary antibody

Incubation-secondary antibody

Chromogen and counterstain

Counterstain

\section{Excessive background staining}

a. Concentrated form of primary antibody

b. Prolonged primary antibody incubation period

c. If primary antibody is from a similar or identical species as the test tissue (e.g., mouse on mouse)

d. Either inadequate buffer washes-inappropriate buffer ion concentration

\section{Remedies}

a. Repeat the procedure with quenching

b. Increase concentration of blocking agent and use a different blocking agent

c. Use an avidin-biotin blocking step or nonavidin-biotin detection method

d. Use an avidin-biotin blocking step or a nonavidinbiotin detection method.

e. Use blocking serum from the same species as the link (secondary) antibody

a. Retitrate primary antibody

b. Reduce incubation time

c. Use specific protocols (i.e., MOM or similar kits) or additional blocking steps

d. Modify ionic strength of the buffer solution

d. Modify ionic strength of the buffer solution

a. Prepare and formulate fresh solution from fresh stock

b. Standardize the timings of incubation

c. Perform proper buffer washes for $5 \mathrm{~min}$

c. Insufficient buffer washes Recognition of endogenous immunoglobulins by secondary antibody

d. Contamination of primary antibody solution by microbes

Excessive background staining

a. Increased concentration of chromogen

b. Treatment of slide with chromogen for longer duration

c. Insufficient buffer wash

a. Conceals the IHC reaction

b. Increased flakes/crystals of hematoxylin d. Add antimicrobial agents, maintain proper storage systems for reagents

a. Reduce concentration of chromogen

b. Reduce incubation time with chromogen

c. Increase the duration of buffer wash

a. Preferential use of a different counterstain that does not interfere with IHC staining

b. Demount the slide and clear the slide with xylene and repeat the step of counterstaining with hematoxylin Filter the hematoxylin before the counterstain step 


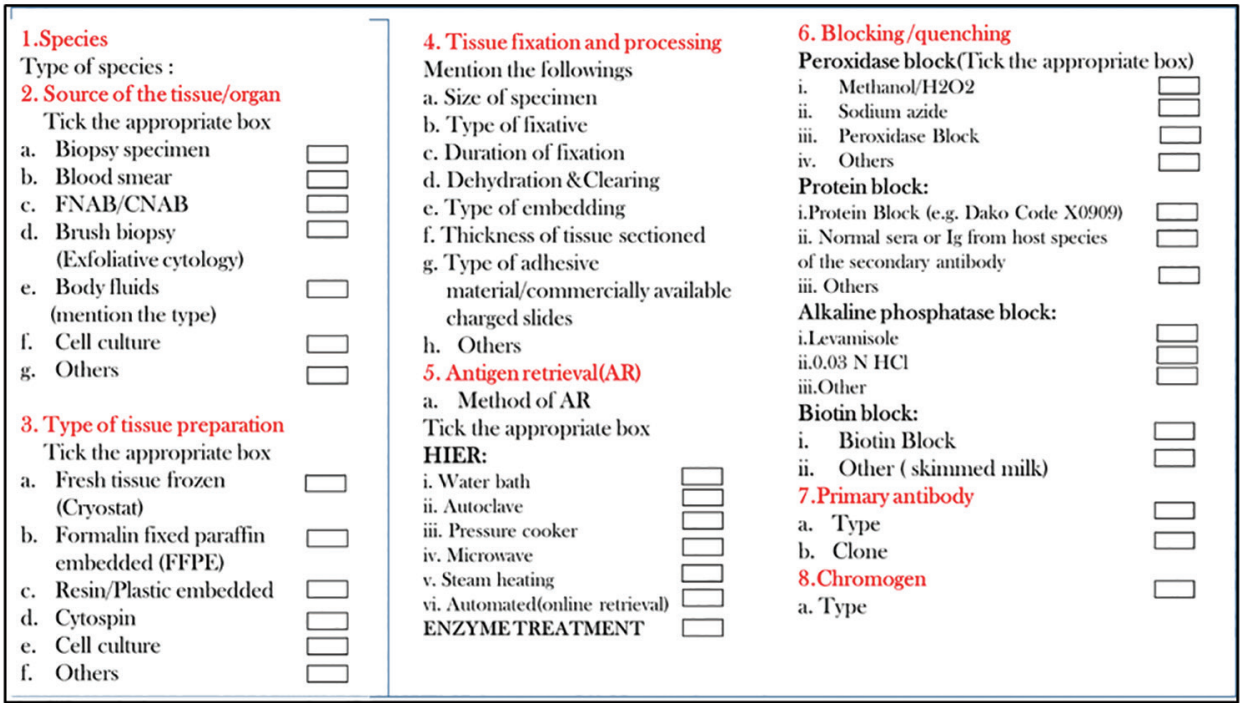

Fig. 2: Checklist for an ideal immunohistochemical staining

- Endogenous biotin interference: This is caused by the biotin (vitamin $\mathrm{H}$ ) present in the living cells predominantly seen in cells of liver, kidney, heart, brain, and lung tissues. Biotin present in the cells utilizes tetrameric biotin-binding proteins from avidin, streptavidin resulting in high background staining/ nonspecific staining. This can be prevented by treating the tissue with avidin before the streptavidin incubation or bind all endogenous biotin moieties with excess streptavidin, then block remaining streptavidin biotin-binding sites with free biotin followed by distilled water wash. ${ }^{14}$

- Nonspecific ionic reactions: The working antibody and test tissue contain net opposite charge leading to ionic interactions that in turn results in nonspecific staining of the tissue. Ionic interaction can occur either due to van der Waals forces or weak electrostatic reaction between dipolar molecules. To prevent this ionic strength of an antibody, diluent buffer or fixative can reduce the ionic interaction, thus reducing the nonspecific staining; but this can weaken the action of monoclonal antibodies than the polyclonal type..$^{15,16}$

- Nonspecific hydrophobic interactions: Hydrophobic reactions can also increase the nonspecific staining due to the neutral side chains of several amino acids. This can be prevented by choosing an appropriate heat-inactivated normal serum or bovine serum and also reagents like nonfat milk, casein, Tween 20, Triton $\mathrm{X} 100$ or by increasing the $\mathrm{pH}$ of the diluent used. ${ }^{14}$

\section{Choice of Diluent, Dilution of Antibodies, and Incubation of Antibodies}

Many of the antibodies for IHC studies are available in concentrated forms; these need to be diluted before the incubation to get appropriate results. As true and false positivity of immunostain could be affected by the tittering of the antibodies of concern, buffer solutions are used to dilute before using these antibodies as a diagnostic or research marker. The ideal dilution of the primary antibody is the titer with highest ratio of specific reaction to background labeling (i.e., signal to noise). The ideal titer should be able to produce noticeable differences in the labeling intensity within samples in such a way that strong and weak positive reactions are distinguishable from the negative reaction, as these ranges of labeling are utmost important in diagnosis and prognosis.

Antibody dilutions of one type of tissue might not be the same as another type. To start with, the dilution of antibodies, the manufacturer's data sheet on antibody performance can be used as a guide for initial dilution. The working concentration of primary antibody should be 1 to $5 \mathrm{mg} / \mathrm{mL}$ and for secondary antibody, 5 to $10 \mathrm{mg} / \mathrm{mL}$, depending upon the type of antibody and quality of the same. This can be reduced with AR procedures.

\section{Primary Antibody}

Primary antibody is the principal step employed for the detection of specific marker in tissues. Selection of proper antibody of test with analytical conditions that are applied to the analyte has an impact on the IHC staining. Every new antibody subjected to IHC for diagnosis and research purposes must be technically optimized prior to the actual procedure. The antibody must subsequently be validated, providing data of the diagnostic sensitivity and specificity, using the protocol identified and selected. ${ }^{16,17}$ The primary antibody has to be incubated for 1 hour at room temperature (37fC) and it varies according to the antibody reactivity. The intensity of staining depends upon various factors such as duration of tissues preserved in formalin, time, and $\mathrm{pH}$, and antibody can lose 
its potency for target epitope due to protein degradation and denaturation. ${ }^{16}$ It can be corrected by maintaining the antibody diluent at 7.0 to $8.2 \mathrm{pH}$ and using the consistent time and temperature during incubation. The optimal primary antibody titration depends upon various factors like choice of appropriate AR, tissue for positive and negative immune-reactivity and also on the storage. Immunohistochemical staining intensity by many antibodies decreases after long-term storage in formalin fixative due to the lack of epitopes in the tissues. ${ }^{18}$

\section{Secondary Antibody}

The commonly used secondary antibodies are affinity purified antibodies. They show an affinity on nontarget antigen of the same epitope that results in secondary antibody cross-reactivity. ${ }^{14}$ Choosing secondary antibody against the host species of primary antibody prevents its cross-reactivity, e.g., if primary antibody in mouse is IgG2a, then antimouse IgG2a can be used. ${ }^{16}$ Saline with tween 20 plus $5 \%$ normal goat serum for 1 hour at $37^{\circ} \mathrm{C}$ reduces the concentration of secondary antibody. ${ }^{16}$ In specific concentration, secondary antibody attaches the primary antibody for detection of antigen. But in high concentrations, the secondary antibody will produce high background staining and reduce antigen detection. ${ }^{14}$ This can be prevented by maintaining the proper optimal concentration of the same. ${ }^{16}$

\section{Chromogen and Counter staining}

The antigen-antibody reaction is usually not visible under the microscope unless labeled. The most common labels are enzymes, particularly peroxidase and alkaline phosphatase. Each enzyme has specific substrates and chromogens to produce a colored precipitate. The commonly used chromogens in IHC produces brown, red, or blue color to the immunoreaction. The selection of development of reaction product depends upon numerous factors like intensity of reaction, localization of antibody, presence or absence of endogenous pigments, and type of mounting media. Most of the laboratories prefer peroxidase as labels over alkaline phosphatase due to its increased sensitivity. ${ }^{19}$

The chromogen of choice in the absence of endogenous pigments for peroxidase labels is usually 3,30-diaminobenzidine tetrachloride that is insoluble in organic solvents, resulting in enhanced staining of the tissue. In case of high activity of endogenous peroxidase or the presence of melanin pigment other chromogens like 3-amino-9-ethylcarbazole or alkaline phosphatase should be used to avoid high background staining. ${ }^{19}$

To improve on the visibility of immunoreactivity, the tissue treated with chromogen and labels can be subjected to postchromogenic enhancement by treating with copper sulfate, osmium tetraoxide, cobalt chloride, or nickel solutions. ${ }^{19}$

Finally the postchromogenic treatment tissue slides are subjected to counterstaining, as it has high impact on the final staining and visibility of immunoreactivity. There are many counterstains available in market; to the best of our knowledge, hematoxylin is one of the best counterstain solutions used in day-to-day practice in the field of $\mathrm{IHC}^{20}$

\section{POSTANALYTICAL PHASE}

The quality of results of experimental test always depends upon the reagents, analyte, technique, controls for the test, and, finally, the interpretation of the data. The postanalytic phase depends totally on the person interpreting the slides and is skill-based rather than technical excellence. The pathologist should be well versed with the patterns of staining produced by the particular types of antibody that is subjected to test and their specific reactivity to the tissues subjected for the same. Pathologist should be in position to identify the false-positive and false-negative reactions of antibodies with tissues. This phase highlights on the importance of control performance, slide interpretation, and reporting of the IHC-stained slide.

\section{Control Performance}

Validation and interpretation of IHC stained slide depends upon the controls used for the test, like any other staining techniques as a reference. It is an essential step of quality control for IHC to validate the specific binding of particular antibody in positive and negative controls. There is no standard definition or agreement on which type of specimens or tissues to be used for positive and negative controls and sets of slides to be performed as controls. ${ }^{1,21}$

"Positive control" in IHC procedure is the specimen/ tissue containing target molecules in its known location or position like cell type, intercellular organelles, nucleus, etc. Their cellular or cytomorphology would be visualized by a stain from a chromogenic molecule. The positive controls are usually anatomical control where their existence or presence of specific antigen is known prior. Also, it is not the experimental or test treatment. There are two types of positive controls, external and internal positive controls. Invariably, positive control is performed in the absence of internal control that is usually present in the test tissue sample. ${ }^{21,22}$

"Negative control" is a tissue type which does not express the protein/antigen of our interest and its main aim is to determine the reaction visualized due to the interaction of epitope of target molecule and paratope of an antibody solution. ${ }^{22}$

Early recognition of omission or improper usage of controls can prevent the severe problems encountered 
during the IHC. Hence, appropriate use of controls in IHC is must. ${ }^{21}$

\section{Interpretation of IHC-stained Slide and Reporting}

Interpretation of IHC-stained slide depends upon the observer (pathologist) and can vary from person to person as it becomes subjective. There is no universal method of interpreting the IHC slide, definitive cut-off to score and agree upon. It is impossible to have an appropriate cut-off value for diagnostic immunomarkers due to impractical issues. Literature search suggests $5 \%$ as a cut-off range to define positive and negative staining. Pathologists interpreting the slide should be sound with the knowledge of test antibody. Interpretation of IHC slides could be influenced by many factors: size of biopsy, quantity of target antigen in the tissue, sensitivity of primary antibody, specificity of test antigen, localization of target antigen (cytoplasmic/nuclear or membranous), controls staining and fixation of the tissue. The most common error encountered during interpretation by the observer would be false-negative result than false-positive. This can be overcome by using best internal positive control. ${ }^{19}$

\section{Aging and Storage of the Slides}

Storage of FFPE tissue sections is a common practice in most of the pathology laboratories, as it advances the efficiency, consistency and quality of tissue sections. During the process of storage, there are high chances of tissue oxidation that results in loss or reduces the specificity of antigen in the tissue toward immunoreactivity. The exact reason for loss of antigen specificity in stored sections is still unclear. But, literature search suggests that it could be due to many environmental factors like temperature, light, adhesive material, type of antibody, and localization of the antibody. Many studies have shown that nuclear markers are more sensitive to the prolonged storage of tissue. Hence, tissue sections older than 12 weeks should not be taken for immunohistochemical staining. Also, the tissues for immunohistochemical staining are dependent on the antigen, storage time, exposure to the light and temperature that are directly proportional to the staining intensity of IHC marker. ${ }^{28}$ We can also observe yeast growth on the IHC-stained slide that is frequently seen as an artifact due to secondary contamination of stored slide in storage cabinets and slide trays. These growths can be easily identified and rectified by periodic washing of slide trays and cabinets using diluted bleaching solutions. ${ }^{28,29}$

\section{CONCLUSION}

Immunohistochemistry is a well-known adjuvant technique for the diagnosis of pathologies and is practiced commonly in day-to-day vogue. Immunohistochemical process involves a series of complex steps that depends upon a trial and error method by standardizing the technique for antibody of interest. So, this review has highlighted the important issues encountered during IHC procedure with their possible remedies and few cardinal rules for IHC that can help a pathologist to obtain an ideal IHC staining results in minimizing the errors.

\section{REFERENCES}

1. Miller RT. Technical immunohistochemistry. Achieving reliability and reproducibility of immunostains. Society for Applied Immunohistochemistry. Annual Meeting New York Cornell-Queens Hospital Medical Center, Flushing, NY; 2001. pp. 1-50.

2. Nadji M, Nassiri M, Vincek V, Kanhoush R, Morales AR. Immunohistochemistry of tissue prepared by a molecularfriendly fixation and processing system. Appl Immunohistochem Mol Morphol 2005 Sep;13(3):277-282.

3. Howat WJ, Wilson BA. Tissue fixation and the effect of molecular fixatives on downstream staining procedures. Methods 2014 Nov;70(1):12-19.

4. Daneshtalab N, Doré JJ, Smeda JS. Troubleshooting tissue specificity and antibody selection: procedures in immunohistochemical studies. J Pharmacol Toxicol Methods 2010 Apr;61(2):127-135.

5. Werner M, Chott A, Fabiano A, Battifora H. Effect of formalin tissue fixation and processing on immunohistochemistry. Am J Surg Pathol 2000 Jul;24(7):1016-1019.

6. Chatterjee S. Artefacts in histopathology. J Oral Maxillofac Pathol 2014 Sep;18(4):111-116.

7. Kyclová J, Rotterová P, Dvořák K, Lukáš Z. Effect of fixation and autolysis on immunohistochemical detection of $\mathrm{CD}$ antigens. Scripta Medica (Brno) 2004 Apr;77(2):63-74.

8. Farrell DJ, Thompson PJ, Morley AR. Tissue artefacts caused by sponges. J Clin Pathol 1992 Oct;45(10):923-924.

9. Shi SR, Cote RJ, Taylor CR. Antigen retrieval immunohistochemistry: past, present and future. J Histochem Cytochem 1997 Mar;45(3):327-343.

10. Shi SR, Cote RJ, Taylor CR. Antigen retrieval techniques: current perspectives. J Histochem Cytochem 2001 Aug;49(8): 931-937.

11. Gown AM, de Wever N, Battifora H. Microwave-based antigenic unmasking a revolutionary new technique for routine immunohistochemistry. Appl Immunohistochem 1993 Jan;1(4):256-266.

12. Okoye JO, Nnatuanya IN. Immunohistochemistry: a revolutionary technique in laboratory medicine. Clin Med Diagn 2015;5(4):60-69.

13. R\&D Systems. Canada USA. Available from: https://www. rndsystems.com/resources/protocols/preventing-nonspecific-staining [accessed 4 November 2016].

14. Novus Biologicals a bio-technical brand, USA. Available from: https://www.novusbio.com/blocking-non-specificbinding2009 [accessed 15 December 2016].

15. IHC world Life science product \& services. Available from: http://www.ihcworld.com/_technical_tips/peroxidase_tips. html [accessed 10 November 2016].

16. Radulescu RT, Boenisch T. Blocking endogenous peroxidases: a cautionary note for immunohistochemistry. J Cell Mol Med 2007 Nov;11(6):1419. 
17. Kalyzuzhny AE. Primary antibodies. In Immunohistochemistry. Techniques in life science and biomedicine for nonexpert; 2016. pp. 3-9.

18. Mirlacher M, Kasper M, Storz M, Knecht $Y$, Dürmüller U, Simon R, Mihatsch MJ, Sauter G. Influence of slide aging on results of translational research studies using immunohistochemistry. Mod Pathol 2004 Jun;17(11):1414-1420.

19. Immunohistochemistry $A B$. Immunohistochemistry Staining Methods. Education Guide, 5th ed.; 2009. p. 57.

20. Hewitt SM, Baskin DG, Frevert CW, Stahl WL, Rosa-Molinar E. Controls for immunohistochemistry: the Histochemical Society's standards of practice for validation of immunohistochemical assays. J Histochem Cytochem 2014 July;62(10): 693-697.

21. Lin F, Chen Z. Standardization of diagnostic immunohistochemistry: literature review and Geisinger experience. Arch Pathol Lab Med 2014 Dec;138(12):1564-1577.

22. Xie R, Chung J-Y, Ylaya K, Williams RL, Guerrero N, Nakatsuka N, Badie C, Hewitt SM. Factors influencing the degradation of archival formalin-fixed paraffin-embedded tissue sections. J Histochem Cytochem 2011 Apr;59(4):356-365.
23. Sanderson C, Emmanuel J, Emmanual J, Campbell P. A historical review of paraffin and its development as an embedding medium. J Histotechnol 1988 Mar;11(1):61-63.

24. Jones ML. How formalin affects the outcome of routine and special stains. Biotech Histochem 2007 Jan;82(3):155-159.

25. Anon. 1st ed. [ebook]. Available from: http://histologylab. ccnmtl.columbia.edu/HistologyLabManual.pdf. 2016.

26. Montero $C$. The antigen-antibody reaction in immunohistochemistry. J Histochem Cytochem 2003 Jan;51(1):1-4.

27. Economou M, Schöni L, Hammer C, Galván JA, Mueller DE, Zlobec I. Proper paraffin slide storage is crucial for translational research projects involving immunohistochemistry stains. Clin Transl Med 2014 Dec;3(1):1-3.

28. Vara JAR, Webster JD, DuSold D, Miller MA. Immunohistochemical evaluation of the effects of paraffin section storage on biomarker stability. Vet Pathol 2014 Jan;51(1):102-109.

29. Baunoch DA, Gooch G, Kraus CA, Kraus KJ, Stephens R. Troubleshooting problems in processing, staining.

30. Wynnchuk M. Minimizing artifacts in tissue processing: part 2. Theory of tissue processing. J Histotechnol 1993 Mar;16(1):71-73. 